\title{
Rotating Internal Damping in the Case of Composite Shafts
}

\author{
G. Jacquet-Richardet, E. Chatelet, T. Nouri-Baranger \\ Université de Lyon, CNRS \\ INSA-Lyon, LaMCoS UMR5259 \\ Villeurbanne F-69621, France
}

\begin{abstract}
There is an increasing range of applications for rotors made of composite materials and operating at supercritical speeds. Design of such structures involves specific features which have to be accounted for in order to allow safe operations. A proper modeling of the mechanical characteristics of the composite is first needed. But, as far as the structure is rotating, the effect of stress stiffening and spin softening may be considered and the effect of internal damping has to be studied in order to avoid possible instability. Internal or rotating damping modeling remains an active field of research where both theoretical developments and experimental results are needed.
\end{abstract}

Keywords: Rotating Shaft, composite material, instability, internal damping, rotating damping.

\section{Introduction}

Damping, coming from different sources, is one of the most difficult issues for structural dynamic predictions. Damping effects are mainly modeled using viscous and hysteretic damping. The main difference between both types of damping is that the energy dissipated per cycle by viscous damping is frequency (spin speed) dependent, whereas the energy dissipated by hysteretic damping is not. Damping associated to the non-rotating parts of the structure has a usual stabilizing effect while damping associated to rotating parts can trigger instability in supercritical ranges. Internal viscous damping is well known. Hysteretic damping is often substituted by an equivalent viscous damping for harmonic motions.

First investigations by Newkirk [1] showed that rotors may experience violent whirling at speeds above the first critical due to internal damping. Since then, many researchers have studied the combined influence of internal (material, dry friction) and external damping (bearings...). Classical results were obtained, showing that rotor stability is improved by increasing the damping provided by the bearings, whereas increasing internal damping may reduce the instability threshold 
[2-4]. Genta [5] demonstrated that an error is made when considering that hysteretic rotating damping is destabilizing at any speed. Until now internal rotating damping modeling remains an up to date research area $[6,7 \ldots]$.

Because of the specific strength and stiffness of high performance fiber reinforced materials, attempts are being made to replace metal shafts by composite ones in many applications: driveshafts for helicopters and cars, centrifugal separators, cylindrical tubes [8-10]. These materials provide advantages in terms of weight reduction and give designers the possibility of obtaining predetermined behavior by changing the arrangement of the composite layers [11,12]. For a rotor made of composite materials, internal damping can be significant [13] due to the damping capacity of the matrix. Optimization techniques have been used in order to avoid instability, minimize the unbalanced response and maximize the stability limit speed. For composite shafts, equivalent modulus beam theory (EMBT) based on classical laminate theory, has many limitations [14], and is only valid for symmetric stacking. General homogenized beam theory (GHBT) has been developed to reduce the previous limitations [15]. The equivalent flexural moduli are in this case evaluated using the Young's modulus, shear modulus and specific damping capacity of each layer. The distance to the neutral axis and the thickness of each layer are explicitly taken into account. Shear effects are considered by evaluating the flexural warping function.

Beam based models are generally useful but may also be questionable. In the case of tubes, multilayered shell models may be needed. Finally, most of the published studies remain purely numerical and there is a lack of experimental results that may be used for a better understanding of the effect of rotating damping as well as for validation purpose [16, 17].

This paper gives first some brief descriptions of the theoretical background concerning internal damping modeling and the equations of motions. Then, applications are presented in order to illustrate and discuss specific features.

\section{Equations of motion - Composite rotor}

Most existing rheological models are based on the combination of elastic and viscous basic elements such as those of Maxwell, Hook and Kelvin-Voigt [18]. In this work, the Kelvin-Voigt model has been chosen. It consists of a spring and a damper in parallel and is commonly used for linear viscoelastic systems. The associated equations of motion of the rotor [19] are, in the rotating frame:

$$
[M]\{\ddot{d}\}+\left[C_{i}+C(\Omega)\right]\{\dot{d}\}+\left[K+K_{i}(\Omega)\right]\{d\}=\{0\}
$$

where $[M]$ represents the mass, $\left[\mathrm{C}_{\mathrm{i}}\right]$ the internal damping, $[\mathrm{C}(\Omega)]$ includes an antisymmetric gyroscopic matrix (function of $\Omega$ speed of rotation) and a frequently asymmetric matrix owing to the characteristics of bearings, $[\mathrm{K}]$ is the 
elastic stiffness matrix and $\left[\mathrm{K}_{\mathrm{i}}(\Omega)\right]$ is the stiffness matrix associated to internal damping as well as stress stiffening and spin softening effects. $\{\ddot{d}\},\{\dot{d}\}$ and $\{d\}$ are respectively nodal accelerations, velocities and displacements. The Campbell diagram and instability regions are determined from the solution of the eigenvalue problem obtained after reduction by the pseudo modal method [19]. The natural frequencies are obtained from the imaginary part and stability criterion is defined from the real part of the eigenvalues.

Considering formulations based on beam theories and dealing with homogeneous materials, the stiffness of the structure is a function of the product EI, where E is the Young's modulus and I the inertia of the section. Similarly, dissipation due to internal damping is a function of EI $\eta$, where $\eta$ is the loss factor. When considering composite rotors, two formulations may be used. The most classical one uses equivalent homogenized material approaches and leads to the Equivalent Modulus Beam Theory (EMBT). On the other hand, General Homogenized Beam

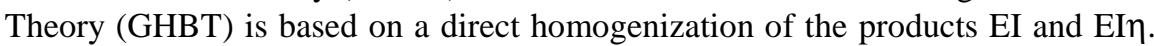
GHBT has the advantage of being valid for any laminate stacking of the rotor wall. The homogenized parameters of the rotor are derived from the strain energy and are expressed as follows [15]:

$$
\begin{aligned}
& E I=\sum_{k=1}^{N} E^{k} \pi\left(\frac{R_{k}^{4}-R_{k-1}^{4}}{4}\right) \quad E I \eta=\sum_{k=1}^{N} E^{k} \eta^{k} \pi\left(\frac{R_{k}{ }^{4}-R_{k-1}{ }^{4}}{4}\right) \\
& E^{k}=\frac{1}{\frac{c^{4}}{E_{l}}+\frac{s^{4}}{E_{t}}+c^{2} s^{2}\left(\frac{1}{G_{l t}}-2 \frac{v_{t l}}{E_{t}}\right)}
\end{aligned}
$$

with: $E_{1}, E_{t}, v_{t l}, G_{l t}$ respectively Young's moduli, Poisson's ratio and shear modulus in the orthotropic axes, $c=\cos (\theta) s=\sin (\theta), R_{k}, R_{k-1}$ give the beginning and the end of the kth layer from the neural axis, $\theta$ is the layer orientation angle and $\mathrm{E}^{\mathrm{k}} \eta^{\mathrm{k}}$ is the damped Young modulus of layer $\mathrm{k}$ along the rotor axis. Damping factor $\eta$ is obtained from the specific damping capacity of layers according to the longitudinal, transversal and shear directions respectively. For the effect of transverse shear, the homogenized shear modulus GS is obtained from the shear strain energy.

\section{Application}

Two different applications are presented and used for illustration. The first one concerns a thin wall composite shaft and the second a composite rotor with discs. 


\subsection{Thin walled composite shaft}

The application considered first is a simply supported thin-walled tube with two lateral inner discs at both ends. The shaft length is $\mathrm{L}=1.5 \mathrm{~m}$, its outer diameter is $\mathrm{D}=0.09 \mathrm{~m}$ and its wall thickness is $\mathrm{e}=7.010^{-4} \mathrm{~m}$. The discs lie at a distance of 0.05 $\mathrm{m}$ from both ends of the tube, their thickness is $3.010^{-3} \mathrm{~m}$ and their inner radius is $0.0075 \mathrm{~m}$. The shaft is made of 5 layers of Boron/Epoxy $\left(\rho=1600 \mathrm{~kg} / \mathrm{m}^{3}, \mathrm{E}_{1}=3.0\right.$ $10^{11} \mathrm{~Pa}, \mathrm{E}_{2}=6.210^{9} \mathrm{~Pa}, \mathrm{G}_{12}=\mathrm{G}_{13}=\mathrm{G}_{23}=4.110^{9} \mathrm{~Pa}$ and $\left.v_{12}=0.26\right)$. The stacking sequence considered is $\left[0^{\circ},-30^{\circ},+30^{\circ}, 0^{\circ}, 90^{\circ}\right]$, given from the inner to the outer surface of the cylinder. Mechanical damping is here neglected.

As shown in Fig. 1, only $1 / 12^{\text {th }}\left(30^{\circ}\right)$ of the whole structure is meshed using a multilayered shell element, constructed from the solid isoparametric element with 16 nodes, by applying Reissner-Mindlin hypotheses. The resulting element is geometrically characterised by 16 nodes and kinematically by 8 nodes and 5 dof per node. A shear correction coefficient equal to $5 / 6$ is considered and reduced integration is used to prevent shear locking.

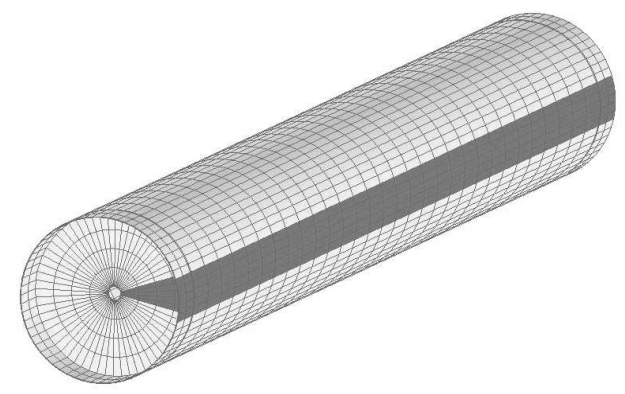

Fig. 1 Cylindrical tube. Only $1 / 12^{\text {th }}$ of the mesh (dark) is considered by the numerical model

Table 1. Natural frequencies at rest $(\mathrm{Hz})$ and first critical speeds (rpm).

\begin{tabular}{cccccc}
\hline Freq. at rest & Freq. at rest & $\Delta(\%)$ & Critical speed & Critical speed & $\Delta(\%)$ \\
Rotorinsa & 3D Model & & Rotorinsa & 3D Model & \\
508.4 & 475.4 & 6.7 & 31820 & 28570 & 11.4 \\
1749.2 & 1446.7 & 18.9 & 116625 & 91660 & 27.2 \\
3305.7 & 2564.7 & 24.0 & & & \\
\hline
\end{tabular}

The three first bending frequencies obtained for the structure at rest are reported in Table 1. These values are compared with those computed using ROTORINSA [19] associated with an EBMT. Differences in results are significant and can be explained by the effect of the simplifying assumptions associated with EBMT: a/ contribution of each layer independent of its radial position, this hypothesis being only valid for thin-walled shafts with symmetrical sequences. b/ longitudinal shear 
deformations associated with bending not considered. Critical speeds obtained with both shell and beam models are also reported. Due to stress stiffening effects, accuracy of the beam model decreases when rotation speed increases.

\subsection{Composite rotor with two discs}

In order to emphasize the influence of internal damping in rotordynamic analysis, Campbell diagram and instability thresholds are determined for a rotor made of a filament wound shaft when considering different configurations of stacking sequences. The structure, proposed by Pereira [12], is a composite shaft with two rigid steel disks supported by two bearings as shown in Fig. 2. Rotor: $\mathrm{L}=1.2 \mathrm{~m}$, $\mathrm{D}=0.096 \mathrm{~m}, \mathrm{e}=0.008 \mathrm{~m}$, Disc: $\mathrm{D}_{\mathrm{i}}=0.096 \mathrm{~m}, \mathrm{D}_{\mathrm{o}}=0.3 \mathrm{~m}, \mathrm{~h}=0.05 \mathrm{~m}$.

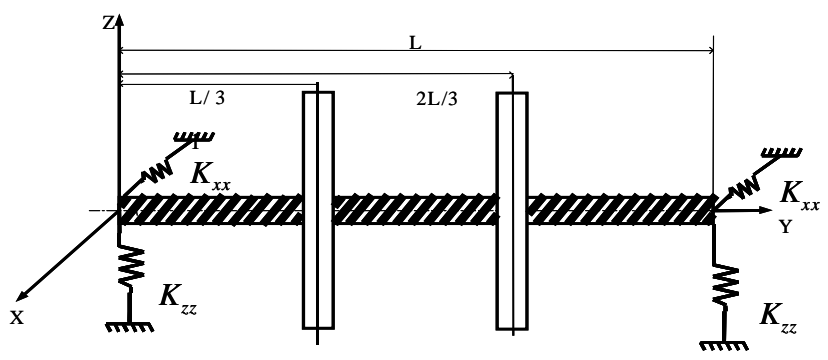

Fig. 2. Filament wound shaft with two disks

Table 2. Material data for the shaft (carbon expoxy)

\begin{tabular}{llllllll}
\hline$E_{l}(\mathrm{GPa})$ & $\mathrm{E}_{\mathrm{t}}(\mathrm{GPa})$ & $\mathrm{G}_{\mathrm{lt}}(\mathrm{GPa})$ & $v_{t l}$ & $\rho\left(\mathrm{kg} / \mathrm{m}^{3}\right)$ & $\psi_{1} \%$ & $\psi_{\mathrm{t}} \%$ & $\psi_{\mathrm{lt}} \%$ \\
172.7 & 7.20 & 3.76 & 0.3 & 1446.2 & 0.45 & 4.22 & 7.05 \\
\hline
\end{tabular}

Material properties of each ply made of carbon/epoxy are summarized in Table 2 and the anisotropic bearing stiffness characteristics are: $\mathrm{Kxx}=1.10^{7} \mathrm{~N} / \mathrm{m}$, $\mathrm{Kzz}=1.10^{8} \mathrm{~N} / \mathrm{m}, \mathrm{Kxz}=\mathrm{Kzx}=0$ (no external damping considered). The first configuration consists in 8 plies of $0.001 \mathrm{~m}$ thickness in a balanced and symmetric configuration $\left[ \pm \theta^{\circ}\right]$ s. Figure 3 gives the Campbell Diagram obtained using GHBT. Frequencies and instabilities thresholds are in this case in very good agreement with those obtained by Pereira using EMBT. As there is no external damping, instability occurs just after the critical speed. 
The same structure with different symmetrical and asymmetrical stacking sequences is then considered. When examining Table 3, the influence of stacking on the first frequency as well as on the instability threshold appears clearly.

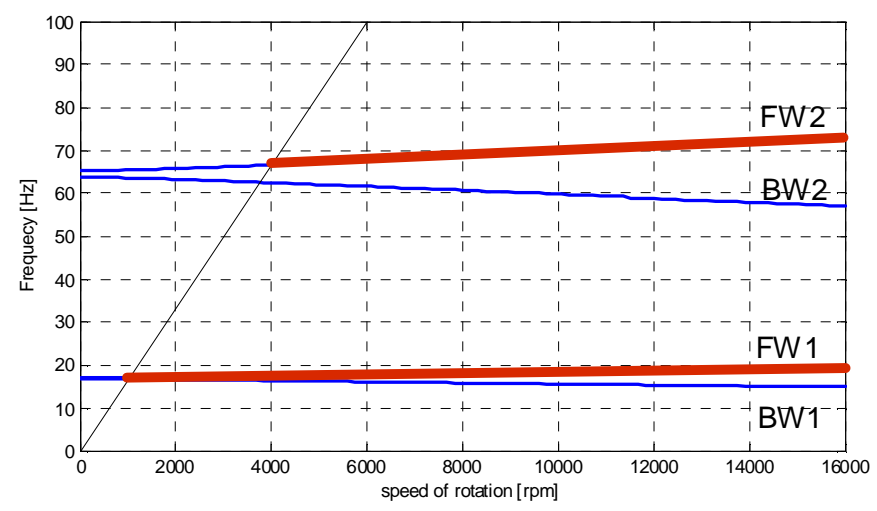

Fig. 3. Campbell diagram and instability regions for a laminate $\theta=75^{\circ}$ with anisotropic bearings $($ red $=$ unstable $)$

Table 3. Mechanical characteristics of the shaft

\begin{tabular}{lllc}
\hline & Stacking sequence & Freq $(\mathrm{Hz})$ & Instability threshold (rpm) \\
1 & {$\left[90_{2}, 45,0\right]_{\mathrm{S}}$} & 39.87 & 5864 \\
2 & {$[90,0,90,45,90,45,0,90]$} & 40.08 & 5913 \\
3 & {$\left[90,45,0_{2}\right]_{\mathrm{S}}$} & 50.71 & 10981 \\
4 & {$[45,0,45,0,90,0,90,0]$} & 51.36 & 11395 \\
\hline
\end{tabular}

As shown in Table 4, where both results obtained from GHBT and EMBT are compared, the distance to the neutral axis contributes to the calculation of the mechanical characteristics of the rotor with GHBT but not accurately with EMBT. When using EMBT, an error up to $16 \%$ on instability threshold and $7 \%$ on the first frequencies is observed. The Campbell Diagram associated with the second configuration considered above is presented in Fig. 4.

Differences between configurations is up to $21 \%$ for frequencies at rest and about $47 \%$ for instability thresholds, and for different cases, not presented here, the rotor may exceed the third critical speed without generating instability. The greater the number of fibers oriented close to the longitudinal direction of the tube, the more they contribute to shaft rigidity and, consequently, the higher frequencies are. Similarly, the lower the orientation angle, the lower the internal damping due to composite materials is and, consequently, the later instability occurs. 
Table 4. Comparison between GHBT and EMBT. Instability threshold - first frequency.

\begin{tabular}{lccclll}
\hline & $\begin{array}{l}\text { GHBM } \\
(\mathrm{rpm})\end{array}$ & \multicolumn{1}{c}{$\begin{array}{l}\text { EMBT } \\
(\mathrm{rpm})\end{array}$} & $\%$ & $\begin{array}{l}\text { GHBM } \\
(\mathrm{Hz})\end{array}$ & $\begin{array}{l}\text { EMBT } \\
(\mathrm{Hz})\end{array}$ & $\%$ \\
{$\left[90_{2}, 45,0\right]_{\mathrm{S}}$} & 5864 & 6956 & 15.7 & 39.87 & 42.76 & 6.7 \\
{$[90,0,90,45,90,45,0,90]$} & 5913 & 6965 & 15.1 & 40.08 & 42.76 & 6.3 \\
{$\left[90,45,0_{2}\right]_{\mathrm{S}}$} & 10981 & 12064 & 9.0 & 50.71 & 52.37 & 3.2 \\
{$[45,0,45,0,90,0,90,0]$} & 11395 & 12064 & 5.5 & 51.36 & 52.37 & 2.0 \\
\hline
\end{tabular}

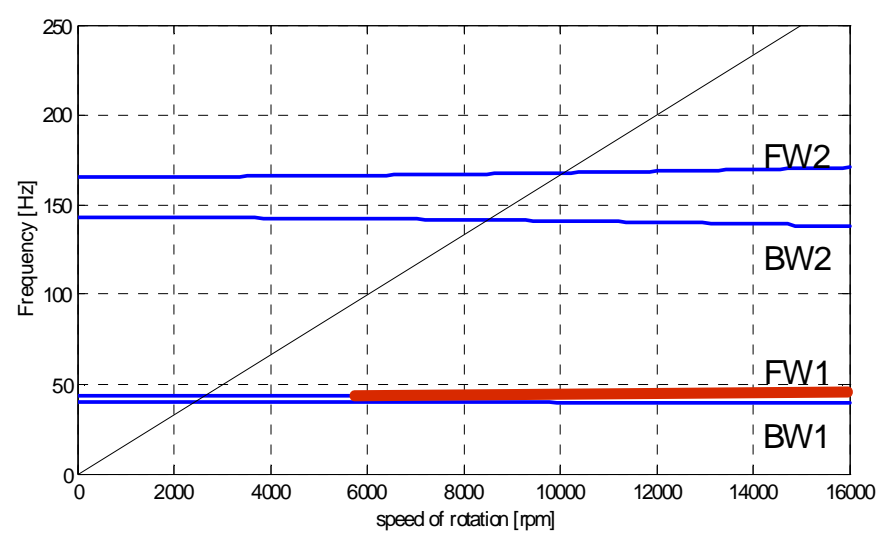

Fig. 4. Campbell diagram for configuration $[90,0,90,45,90,45,0,90]$

\section{Experimental analyses}

An experimental set up developed at the LMA of Marseille France, shown in Fig. 5 is used for illustration and validation. The set up allows studying the stability of shafts made of different materials with various lengths ranging between $0.5 \mathrm{~m}$ and $3 \mathrm{~m}$.

To allow supercritical behavior, passive dissipation is introduced at bearing level using viscoelastic supports (damping factor 3.5\%). Bearings are classical ball bearings. The main characteristics of the tested rotors, made of PVC, are: Young modulus $2.2 \mathrm{GPa}$, density $1350 \mathrm{~kg} / \mathrm{m}^{3}$, external radius $0.025 \mathrm{~m}$, internal radius $0.0215 \mathrm{~m}$, damping factor $1.25 \%$. Isotropic bearing mass is $2.608 \mathrm{Kg}$ and foundation stiffness is $567.10^{3} \mathrm{~N} / \mathrm{m}$. 


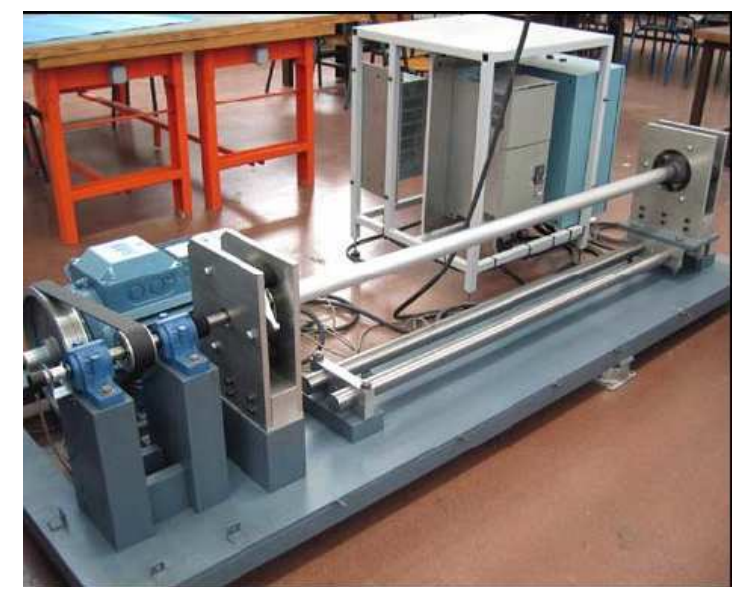

Fig. 5. Testing machine for high-speed tubes

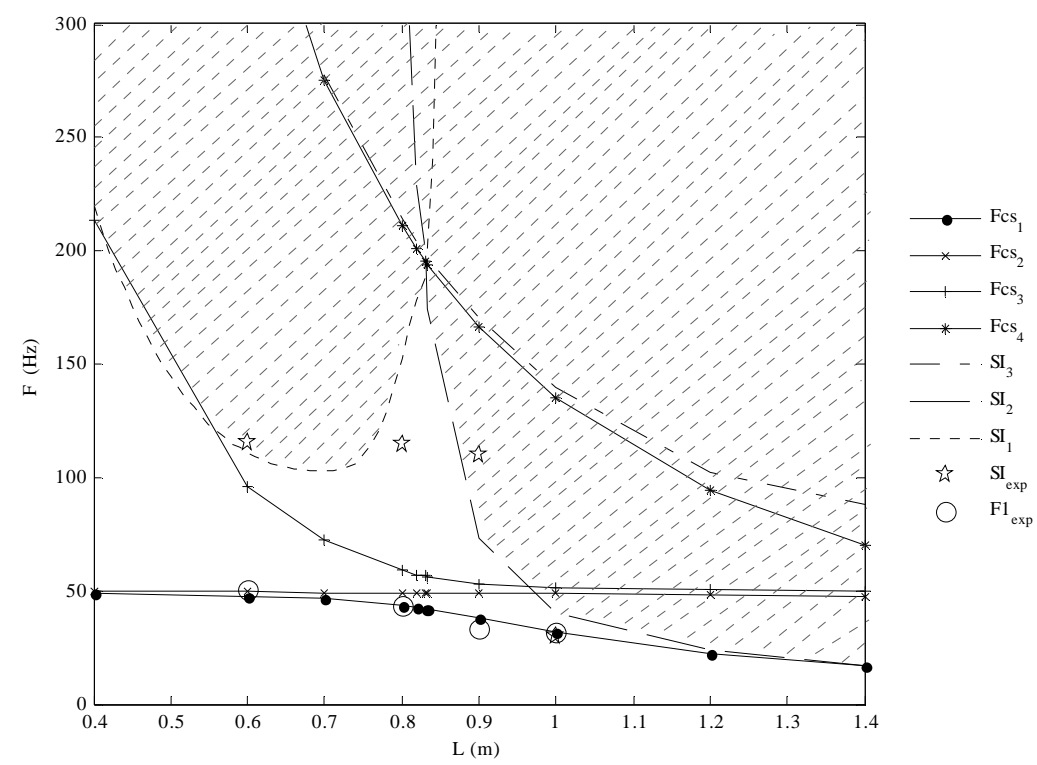

Fig. 6: PVC Tube: numerical and experimental results.

Fig. 6 shows the evolution of the computed frequencies and instability thresholds, with respect to the rotor length L. Legends are as follows: $F_{c s i} i^{\text {th }}$ frequency of the system; $\mathrm{SI}_{\mathrm{i}} \mathrm{i}^{\text {th }}$ associated instability threshold. The instability zone (grey) of this rotor is greater than the instability zone of rotors made of classical materials due to the material damping which is more significant for PVC $(1.25 \%$ here compared to 
0.2 associated to an aluminium rotor for exemple). Experimental results obtained at the LMA are also given. They are symbolized by a circle $\bigcirc$ for the first frequency and by a star $\hat{i}$ for the instability thresholds. Four experimental tests were performed for tubes of lengths $0.6 \mathrm{~m}, 0.8 \mathrm{~m}, 0.9 \mathrm{~m}$ and $1 \mathrm{~m}$. The experimental instability was detected at the first critical speed. Tendencies shown by experimental results are in good agreement with theoretical results and the first frequency identified matches very well.

Observation points out two instability zones merging at a length $\mathrm{L}$ near $0.8 \mathrm{~m}$. Within this zone the different components of the system are highly coupled. Frequencies associated to the rigid rotor with flexible bearings match frequencies of the tube supported by rigid bearings. For this particular length of rotor, bearings are highly responding and then provide more external damping to the system, increasing stability. Such behavior has also been observed by Dutt [20] who shows that a proper selection of the value of support parameters can increase significantly instability threshold for a system on viscoelastic supports.

\section{Conclusion}

The presented paper deals with the dynamical analysis of internally damped rotating composite shafts. Usual rotordynamics modeling is based on beam theories. In this case, the General Homogenized Beam Theory is needed to avoid the main drawbacks associated with formulations that consider only symmetrical and balanced stacking sequences and do not take into account the distance of layers from the neutral axis. As already shown, those simplifications may lead to significant discrepancies in terms of frequencies and instability thresholds. The method also allows accurate characterization of the structure's internal damping, based on the specific damping capacity of each ply of the composite assembly. Another limitation illustrated here concerns the case where the rotating structure is more a tube than a shaft. In this case classical effects such as stress stiffening and spin softening shall be accounted for. Then beam theories are no more valid and shall be replaced by multilayered shell theories.

Finally an experimental set up is described and used for illustration and validation. New techniques are under development and major improvements are clearly needed to overcome the large limitations of the classical equivalent viscous damping model. But the development of those techniques has to be clearly associated with much more fine available experimental results (transient response...)

Acknowledgments The authors wish to thank Pr. C. Hochard from the Laboratoire de Mécanique et d'Acoustique, UPR CNRS 7051 Marseille France and Dr O. Montagnier for providing the experimental data presented in section 4 . 


\section{References}

1. Newkirk B.L., 'Shaft Whipping', General Electric Rev., vol. 27(3), pp. 169-178 (1924).

2. Genta G., 'Dynamics of rotating systems', Springer, New York (2005)

3. Cerminaro A.M. and Nelson F.C, 'The effect of Viscous and hysteretic Damping rotor stability', ASME TURBOEXPO (2000), Munich, Germany.

4. Sino R., Chatelet E., Montagnier O., Jacquet-Richardet G., 'Dynamic instability of internally damped rotors', ASME TURBOEXPO (2007), Montreal Canada.

5. Genta G., 'On a persistent misunderstanding of the role of Hysteretic damping in rotordynamics', Journal of Vibration and Acoustics, Vol. 126, pp. 459-461 (2004).

6. Genta G., 'Time domain simulation of rotors with hysteretic damping', $9^{\text {th }}$ int. Conf on Vibrations in Rotating Machinery, pp 799-810 (2008), Exeter.

7. Vatta F., Vigliani A. 'Internal damping in rotating shafts' Mechanism and Machine Theory, 43 pp. 1376-1384 (2008).

8. Darlow M.S., Creonte J., 'Optimal design of composite helicopter power transmission shafts with axially varying fiber lay-up', Journal of the American Helicopters society, vol. 40(2), pp 50-56 (1995).

9. Singh S.P., Gupta K., 'Damping measurements in fiber reinforced composite rotors', Journal of Sound and Vibration, vol. 211(3), pp513-520 (1998).

10. Chatelet E., Lornage D. and Jacquet-Richardet G., 'A three-dimensional modeling of the dynamic behavior of composite rotors', International Journal for Rotating Machinery, vol. 8(3), pp. 185-192 (2002).

11. Bauchau O., 'Optimal Design of High Speed Rotating Graphite/Epoxy Shafts', Journal of Composite Materials, vol. 17(3), pp. 170-181 (1983).

12. Pereira J.C. and Marcio E.S., 'Evaluation and Optimization of the instability regions on rotors in wounding shaft', II Congresso Nacional de Engenharia Mecânica (2002), João Pessoa, Brazil.

13. Wettergren H.L. and Olsson K.O., 'Dynamic Instability of A Rotating Asymmetric Shaft with Internal Viscous Damping Supported in anisotropic bearings', Journal of Sound and Vibration, Vol. N 195(1), pp75-84 (1996).

14. Singh, S.P. and Gupta, K., 'Free Damped Flexural Vibration Analysis of Composite Cylindrical Tubes Using Beam and Shell Theories', Journal of Sound and Vibration, Vol. 172(2), pp. 171-190 (1994).

15 Sino R., Baranger T.N., Chatelet E., Jacquet G., 'Dynamic analysis of rotating composite shaft', Composite Science and Technology, vol 68(2), pp. 337-345, (2008).

16. Montagnier $\mathrm{O}$ et Hochard $\mathrm{C}$., 'Etude théorique et expérimentale de la Dynamique des arbres de transmission supercritiques', $17^{\text {ว̀me }}$ congrès Français de Mécanique, Troyes, 29 Août-2 Septembre (2005).

17. Montagnier O. et Hochard C.,'Design of supercritical composite helicopter driveshafts: theoretical and experimental study', European conference for aerospace sciences (EUCASS) (2005).

18. Osinski Z. 'Damping of vibrations', Institute of Machine Design Fundamentals', Warsaw university of technology, Poland. A.A.balkema (1998).

19. Lalanne M., Ferraris G. 'Rotordynamics Prediction in Engineering', 2nd edition, J. Wiley and Sons, 254 p (1998).

20. Dutt J.K. and Nakra B.C., 'Stability of rotor systems with viscoelastic supports', Journal of Sound and Vibration, Vol. 153(1), pp. 89-96 (1992). 